\title{
Boundary Layer of Photon Absorption Applied to Heterogeneous Photocatalytic Solar Flat Plate Reactor Design
}

\author{
Héctor L. Otálvaro-Marín, ${ }^{1}$ Miguel Angel Mueses, ${ }^{2}$ and Fiderman Machuca-Martínez ${ }^{1}$ \\ ${ }^{1}$ GAOX Group, Chemical Engineering School, Universidad del Valle, A.A. 25360 Cali, Colombia \\ ${ }^{2}$ Photocatalysis and Solar Photoreactors Engineering, Department of Chemical Engineering, Universidad de Cartagena, \\ A.A. 1382 Cartagena, Colombia
}

Correspondence should be addressed to Héctor L. Otálvaro-Marín; hector.otalvaro@correounivalle.edu.co

Received 28 February 2014; Accepted 12 May 2014; Published 5 June 2014

Academic Editor: Hong Liu

Copyright (c) 2014 Héctor L. Otálvaro-Marín et al. This is an open access article distributed under the Creative Commons Attribution License, which permits unrestricted use, distribution, and reproduction in any medium, provided the original work is properly cited.

\begin{abstract}
This study provides information to design heterogeneous photocatalytic solar reactors with flat plate geometry used in treatment of effluents and conversion of biomass to hydrogen. The concept of boundary layer of photon absorption taking into account the efficient absorption of radiant energy was introduced; this concept can be understood as the reactor thickness measured from the irradiated surface where $99 \%$ of total energy is absorbed. Its thickness and the volumetric rate of photons absorption (VRPA) were used as design parameters to determine (i) reactor thickness, (ii) maximum absorbed radiant energy, and (iii) the optimal catalyst concentration. Six different commercial brands of titanium dioxide were studied: Evonik-Degussa P-25, Aldrich, Merck, Hombikat, Fluka, and Fisher. The local volumetric rate of photon absorption (LVRPA) inside the reactor was described using sixflux absorption-scattering model (SFM) applied to solar radiation. The radiation field and the boundary layer thickness of photon absorption were simulated with absorption and dispersion effects of catalysts in water at different catalyst loadings. The relationship between catalyst loading and reactor thickness that maximizes the absorption of radiant energy was obtained for each catalyst by apparent optical thickness. The optimum concentration of photocatalyst Degussa P- 25 was $0.2 \mathrm{~g} / \mathrm{l}$ in $0.86 \mathrm{~cm}$ of thickness, and for photocatalyst Aldrich it was $0.3 \mathrm{~g} / \mathrm{l}$ in $0.80 \mathrm{~cm}$ of thickness.
\end{abstract}

\section{Introduction}

Heterogeneous photocatalysis based on $\mathrm{TiO}_{2}$ and modified photocatalysts is widely used in energetic and environmental applications, including water and air purification systems $[1,2]$, self-cleaning surfaces [3], wettability patterns, and printing applications [4], and as a clean production route of hydrogen fuel [5]. The first step of photocatalytic reaction mechanism [6] is the radiant energy absorption higher than the band gap of the semiconductor to generate electronhole pairs on its surface, which can initiate oxidation and reduction reactions.

A clean route for hydrogen production has been proposed by photogenerated electrons at the conduction band from reduction of water in the absence of oxygen and oxidation of waste biomass using solar energy [7].
Regarding the mineralization of organic contaminants, Turchi and Ollis proposed a path based on the generation of oxidizing species (Table 1) [6]; adsorbed water on the $\mathrm{TiO}_{2}$ 's surface (reactions $2 \mathrm{a}$ and $2 \mathrm{~b}$ ) reacts with holes to generate hydroxyl radicals (reactions $6 \mathrm{a}$ and $6 \mathrm{~b}$ ). The attack of the hydroxyl radical (reactions 9-12) on a $\mathrm{C}-\mathrm{H}$ bond is the prevailing step for the oxidative breakdown, which is responsible for the mineralization of a wide range of pollutants (e.g., cyanide, arsenic, halogenated hydrocarbons, pesticides, endocrine disruptors, estrogens, inorganics, aromatics, emerging pollutants, and many others) [8-14]. More details of the mechanism and their considerations are in [15].

The above mentioned applications present a trend towards the use of solar energy as a sustainable source of energy, development of efficient reactors geometries, and scale-up of reactors. Therefore, rigorous methodologies have 
TABLE 1: Heterogeneous photocatalysis reaction scheme based on semiconductor $\mathrm{TiO}_{2}$, extracted from Turchi and Ollis [6].

\begin{tabular}{|c|c|c|}
\hline Activation & $\mathrm{TiO}_{2} \stackrel{h v}{\longrightarrow} e^{-}+h^{+}$ & $(1)$ \\
\hline \multirow{4}{*}{ Adsorption } & $\mathrm{O}_{\mathrm{Lattic}}^{2-}+\mathrm{Ti}^{\mathrm{IV}}+\mathrm{H}_{2} \mathrm{O} \rightleftharpoons \mathrm{O}_{\mathrm{L}} \mathrm{H}^{-}+\mathrm{Ti}^{\mathrm{IV}}-\mathrm{OH}^{-}$ & (2a) \\
\hline & $\mathrm{Ti}^{\mathrm{IV}}+\mathrm{H}_{2} \mathrm{O} \rightleftharpoons \mathrm{Ti}^{\mathrm{IV}}-\mathrm{H}_{2} \mathrm{O}$ & $(2 b)$ \\
\hline & Site $+R_{i} \rightleftharpoons R_{i \text {,ads }}$ & (3) \\
\hline & $\mathrm{OH}^{\bullet}+\mathrm{Ti}^{\mathrm{IV}} \rightleftharpoons \mathrm{Ti}^{\mathrm{IV}}-\mathrm{OH}^{\bullet}$ & (4) \\
\hline \multirow[t]{2}{*}{ Recombination } & $e^{-}+h^{+} \rightarrow$ heat & (5) \\
\hline & $\mathrm{Ti}^{\mathrm{IV}}-\mathrm{OH}^{-}+h^{+} \rightleftharpoons \mathrm{Ti}^{\mathrm{IV}}-\mathrm{OH}^{\bullet}$ & $(6 a)$ \\
\hline \multirow[t]{2}{*}{ Hole trapping } & $\mathrm{Ti}^{\mathrm{IV}}-\mathrm{H}_{2} \mathrm{O}+h^{+} \rightleftharpoons \mathrm{Ti}^{\mathrm{iV}}-\mathrm{OH}^{\bullet}+\mathrm{H}^{+}$ & $(6 b)$ \\
\hline & $R_{i, \mathrm{ads}}+h^{+} \rightleftharpoons R_{i, \mathrm{ads}}^{+}$ & (7) \\
\hline \multirow{2}{*}{ Electron trapping } & $\mathrm{Ti}^{\mathrm{IV}}+e^{-} \rightleftharpoons \mathrm{Ti}^{\mathrm{III}}$ & $(8 \mathrm{a})$ \\
\hline & $\mathrm{Ti}^{\mathrm{III}}+\mathrm{O}_{2} \rightleftharpoons \mathrm{Ti}^{\mathrm{IV}}-\mathrm{O}_{2}^{\cdot-}$ & $(8 b)$ \\
\hline \multicolumn{3}{|l|}{ Hydroxyl attack } \\
\hline Case I & $\mathrm{Ti}^{\mathrm{IV}}-\mathrm{OH}^{\bullet}+R_{i, \text { ads }} \rightarrow \mathrm{Ti}^{\mathrm{IV}}+R_{j, \text { ads }}$ & (9) \\
\hline Case II & $\mathrm{OH}^{\bullet}+R_{i, \mathrm{ads}} \rightarrow R_{j, \mathrm{ads}}$ & $(10)$ \\
\hline Case III & $\mathrm{Ti}^{\mathrm{IV}}-\mathrm{OH}^{\bullet}+R_{i} \rightarrow \mathrm{Ti}^{\mathrm{IV}}+R_{j}$ & (11) \\
\hline Case IV & $\mathrm{OH}^{\bullet}+R_{i} \rightarrow R_{j}$ & (12) \\
\hline
\end{tabular}

been developed for design and optimization of photoreactors based on scientific knowledge of the photocatalytic process $[8,9,14,16-18]$, allowing a more economical and technically feasible process.

The rigorous description of photoreactor requires (i) radiation field, (ii) hydrodynamic field, and (iii) mass balance with kinetic expression whose parameters should be independent of photon absorption. The study of the radiation field provides optimal design information such as reactor geometry, catalyst selection, catalyst loading, and dimensions of the reactor $[19,20]$.

The variable most employed to quantify the spatial distribution of radiant energy absorbed within the reactor is the local volumetric rate of photon absorption (LVRPA); it depends on the geometry, radiation source, loading, and type of photocatalyst, in some cases on the pollutant if this presents absorption of radiant energy. A rigorous approach to determine the LVRPA is the solution of the radiative transfer equation (RTE), by the discrete ordinate method (DOM), which requires spatial, directional, and spectral discretizations inside the reactor $[8,20,21]$.

A useful approach is the six-flux absorption-scattering model (SFM); it has been applied to different geometries: compound parabolic collector (CPC) photoreactors [10, 19], annular reactors $[12,13,22-24]$, and flat plate reactors [25]. This model calculates the LVRPA through a system of algebraic equations, where the scattering event can occur only along the six directions of the Cartesian coordinates [25]; it reduces the mathematical complexity to an analytical system, thus saving computational time and effort.

Flat plate reactors are scalable, and these can be used with solar radiation, so they are very attractive and also provide an excellent configuration for efficient excitation of the semiconductor photocatalyst $\mathrm{TiO}_{2}$ [26]; their modeling requires a complex analysis of the radiation field inside the photoreactor [27]. In water treatment, for a dilute pollutant is considered the photon absorption only by the solid photocatalyst particles [28, 29], therefore, the pollutant concentration and the radiation field are decoupled [20, 25] allowing us to separately study the effect of photon absorption of the water-catalyst solution.

In this study, design parameters of a flat plate photoreactor with photocatalysts based on $\mathrm{TiO}_{2}$ and solar radiation were analyzed in terms of absorption of photons. For mathematical convenience, the variable LVRPA $/ I_{0}$ was employed; it is estimated by SFM model and does not require emission model. Also, a new design parameter for selection of the optimum reactor thickness called boundary layer thickness of photon absorption is presented. The information presented might be used in kinetic models of pollutants degradation and hydrogen production.

\section{Methodology}

2.1. Model of Boundary Layer of Photon Absorption. This paper proposes a new concept for heterogeneous photocatalytic reactor design, which allows us to determine the best thickness. Figure 1 shows a schematic representation of a double flat plate reactor with thick $H_{R}$, located perpendicular to the source. Additionally, the figure presents a profile of LVRPA along the $y$-coordinate, with maximum value at the interface surface-flow $\left(\mathrm{LVRPA}_{s}\right)$ and minimum value at reactor bottom $\left(\mathrm{LVRPA}_{\infty}\right)$.

The region where there is a gradient of energy absorption has been called "boundary layer of photon absorption," and its thickness $\delta_{\text {abs }}$ is defined as $y$-value which satisfies the following ratio:

$$
\frac{\operatorname{LVRPA}_{s}-\operatorname{LVRPA}\left(\delta_{\mathrm{abs}}\right)}{\mathrm{LVRPA}_{s}-\operatorname{LVRPA}_{\infty}}=0.99 .
$$

This definition of boundary layer thickness for transport phenomena and absorption of radiant energy is analogous to the definition of thickness of hydrodynamic, thermal, and concentration boundary layer on a flat plate [30]. The $\delta_{\mathrm{abs}}$ 


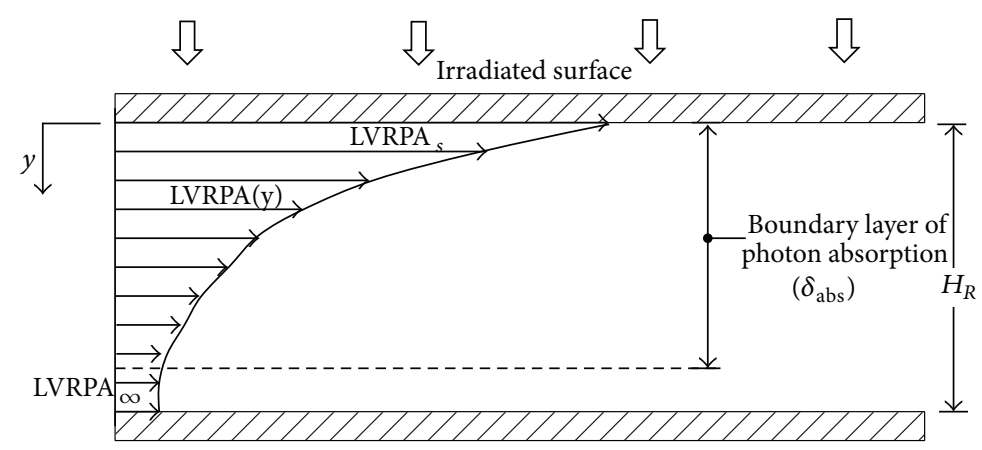

FIGURE 1: Boundary layer of photon absorption in a double flat plate reactor irradiated onto upper plate.

can be understood as the reactor thickness measured from the irradiated surface where $99 \%$ of total energy is absorbed. For this reason, boundary layer thickness becomes a design parameter for selection of optimum thickness of flat plate reactors. Oversizing of reactor thickness can lead to the presence of a dark sublayer, where there is no considerable photon absorption.

This design parameter is similar to the apparent optical thickness used for sizing of annular reactors and CPCs $[19,31]$. The $\delta_{\mathrm{abs}}$ uses the analogous concept of boundary layer thickness to obtain the optimal light absorption. $\delta_{\text {abs }}$ depends of catalyst (type and loading) and it can be used as a geometrical parameter equal to the optimum reactor thickness $H_{R}$ (see Figure 1).

2.2. Volumetric Rate of Photon Absorption VRPA. VRPA is defined as an average value of LVRPA in the whole volume. For a flat plate reactor the VRPA is expressed as [20]

$$
\mathrm{VRPA}=\langle\mathrm{LVRPA}\rangle_{V_{R}}=\frac{1}{H_{R}} \int_{0}^{H_{R}} \operatorname{LVRPA}\left(C_{m, \text { cat }}, y\right) d y .
$$

VRPA is a design parameter established and validated to determine catalyst concentrations in photocatalytic processes [20].

VRPA and boundary layer thickness presented above are design parameters of photoreactors and their calculations require a model of radiant field, which quantify LVRPA within the reactor.

2.3. Radiant Field Model. The radiation field of a reactor with incident solar radiation was modeled by six-flux absorptionscattering model (SFM) [10, 12, 14, 19, 24, 25]. LVRPA divided by flux of incident radiant energy in reactor $I_{0}$ expressed by this model is

$$
\begin{aligned}
& \frac{\text { LVRPA }}{I_{0}} \\
& =\left[\left(\omega_{\text {corr }}-1+\sqrt{1-\omega_{\text {corr }}^{2}}\right) e^{\left(-r_{p} / \lambda_{\omega_{\text {corr }}}\right)}\right. \\
& \left.\quad+\gamma\left(\omega_{\text {corr }}-1-\sqrt{1-\omega_{\text {corr }}^{2}}\right) e^{\left(r_{p} / \lambda_{\omega_{\text {corr }}}\right)}\right] \\
& \quad \times\left(\lambda_{\left.\omega_{\text {corr }} \omega_{\text {corr }}(1-\gamma)\right)^{-1},}\right.
\end{aligned}
$$

where $r_{p}$ is the coordinate of photon, $r_{p}=y$ in a flat plate reactor, $\omega_{\text {corr }}$ is the corrected scattering albedo, $\lambda_{\omega_{\text {co }}}$ corresponds to the corrected value of mean free path of photons in the suspension, and $\gamma$ is a SFM parameter.

The parameters of (3) are function of average values of the scattering and absorption coefficients of catalyst, which are calculated as well:

$$
\begin{aligned}
\left\langle\sigma^{*}\right\rangle & =\frac{\int_{\lambda_{\min }}^{\lambda_{\max }} \sigma_{\lambda}^{*} I(\lambda) d \lambda}{\int_{\lambda_{\min }}^{\lambda_{\max }} I(\lambda) d \lambda} \\
\left\langle\kappa^{*}\right\rangle & =\frac{\int_{\lambda_{\min }}^{\lambda_{\max }} \kappa_{\lambda}^{*} I(\lambda) d \lambda}{\int_{\lambda_{\min }}^{\lambda_{\max }} I(\lambda) d \lambda},
\end{aligned}
$$

where $\lambda_{\min }$ and $\lambda_{\max }$ correspond to 280 y $395 \mathrm{~nm}$, respectively, given by the interception of solar emission spectrum and $\mathrm{TiO}_{2}$ absorption spectrum; $I(\lambda)$ is the spectrum of solar emission power [32]; $\sigma_{\lambda}^{*}$ and $\kappa_{\lambda}^{*}$ are the spectrums of scattering and absorption coefficients, respectively, per mass unit of catalyst, reported in [33] using a phase function with diffuse reflectance for different commercial brands of $\mathrm{TiO}_{2}$.

Extinction coefficient $\beta$ is the sum of the absorption and scattering average coefficients $\beta=\left\langle\kappa^{*}\right\rangle+\left\langle\sigma^{*}\right\rangle$. This parameter is used to calculate the scattering albedo $\omega=$ $\left\langle\sigma^{*}\right\rangle / \beta$ which determines the fraction of dispersed energy.

Scattering albedo requires a correction $\omega_{\text {corr }}$ to the model of six directions [25], through probabilities of forward, backward, and sideways scattering $\left(p_{f}, p_{b}, p_{s}\right)$ :

$$
\omega_{\text {corr }}=\frac{b}{a}
$$

where

$$
\begin{gathered}
a=1-\omega p_{f}-\frac{4 \omega^{2} p_{s}^{2}}{\left(1-\omega p_{f}-\omega p_{b}-2 \omega p_{s}\right)} \\
b=\omega p_{b}+\frac{4 \omega^{2} p_{s}^{2}}{\left(1-\omega p_{f}-\omega p_{b}-2 \omega p_{s}\right)}
\end{gathered}
$$

$p_{f}, p_{b}, p_{s}$ values are $0.11,0.71$, and 0.045 for a phase function of great sphere with diffuse reflectance [10]. Mean free path 
of photons in the suspension $\lambda_{0}$ and its corrected value $\lambda_{\omega_{\text {corr }}}$, which depend on catalyst concentration, are calculated as well [10]:

$$
\begin{gathered}
\lambda_{0}=\frac{1}{\beta C_{m, \mathrm{cat}}} \\
\lambda_{\omega_{\mathrm{corr}}}=\frac{\lambda_{0}}{a \sqrt{1-\omega_{\mathrm{corr}}^{2}}} .
\end{gathered}
$$

Finally, the parameter $\gamma$ is calculated through the following equation:

$$
\gamma=\frac{1-\sqrt{1-\omega_{\text {corr }}^{2}}}{1+\sqrt{1-\omega_{\text {corr }}^{2}}} e^{\left(-2 \tau_{\text {app }}\right)},
$$

where $\tau_{\text {app }}$ is apparent optimal thickness defined as

$$
\tau_{\mathrm{app}}=\tau a \sqrt{1-\omega_{\mathrm{corr}}^{2}}
$$

and $\tau$ is the optical thickness, for a flat plate reactor $\tau=$ $H_{R} / \lambda_{0}[25,26]$.

To obtain the new parameter, boundary layer thickness of photon absorption $\delta_{\text {abs }}$ is proposed to minimize an objective function (10), which is obtained from the definition (1), using the Nelder-Mead optimization algorithm:

$$
\begin{aligned}
F_{\text {obj }}\left(\delta_{\text {abs }}\right) & \\
= & {\left[\left(\operatorname{LVRPA}_{s}-\operatorname{LVRPA}\left(\delta_{\text {abs }}\right)\right)\right.} \\
& \left.\quad-0.99\left(\operatorname{LVRPA}_{s}-\operatorname{LVRPA}_{\infty}\right)\right]^{2},
\end{aligned}
$$

where $\mathrm{LVRPA}_{s}$ and LVRPA ${ }_{\infty}$ correspond to the SFM evaluated in $r_{p}$ equal to zero and $H_{R}$, respectively.

\section{Results and Discussion}

3.1. Optical Properties under Solar Radiation. The SFM parameters that are independent of the catalyst concentration are shown in Table 2 for six different commercial brands of $\mathrm{TiO}_{2}$ and solar radiation using (4)-(6). Parameters of photocatalytic activity are different due to the percentage of anatase, rutile, and brookite present in each trademark.

The values reported here disagree with those reported by [10] for Degussa under the same radiation condition $\left(\left\langle\sigma^{*}\right\rangle=\right.$ $1.30 \times 10^{4}$ and $\left.\left\langle\kappa^{*}\right\rangle=1.75 \times 10^{3}\right)$ due to the use of different phase functions. Colina-Márquez et al. [10] applied optical properties described by Henyey and Greenstein phase function [34]; in contrast, this study employed optical properties of catalyst and scattering probabilities $p_{f}, p_{b}, p_{s}$ from a phase function model of diffuse reflectance $[22,25]$.

3.2. LVRPA. Figure 2 shows the LVRPA/ $I_{0}$ profiles (3) as a function of $y$-coordinate inside a flat plate photoreactor with solar radiation for catalyst Degussa and Aldrich for different catalyst concentrations. The optical properties presented in
TABLE 2: Average optical properties of commercial photocatalysts based on titanium dioxide under solar radiation.

\begin{tabular}{lccccc}
\hline Catalyst & $\begin{array}{c}\left\langle\sigma^{*}\right\rangle \times 10^{-4} \\
\left(\mathrm{~cm}^{2} \mathrm{~g}^{-1}\right)\end{array}$ & $\begin{array}{c}\left\langle\kappa^{*}\right\rangle \times 10^{-3} \\
\left(\mathrm{~cm}^{2} \mathrm{~g}^{-1}\right)\end{array}$ & $\begin{array}{c}\beta \times 10^{-4} \\
\left(\mathrm{~cm}^{2} \mathrm{~g}^{-1}\right)\end{array}$ & $\omega$ & $\omega_{\text {corr }}$ \\
\hline Aldrich & 3.73 & 2.43 & 3.98 & 0.94 & 0.84 \\
Degussa & 5.42 & 2.87 & 5.71 & 0.95 & 0.87 \\
Merck & 2.97 & 2.68 & 3.24 & 0.92 & 0.81 \\
Hombikat & 2.52 & 1.17 & 2.64 & 0.96 & 0.88 \\
Fischer & 1.60 & 2.65 & 1.86 & 0.86 & 0.72 \\
Fluka & 1.64 & 2.89 & 1.92 & 0.85 & 0.71 \\
\hline
\end{tabular}

Table 2 were used. A reactor thickness $H_{R}$ equal to $1 \mathrm{~cm}$ was considered, because it is enough for photon absorption $[20,35]$. Therefore, the dimensionless optical thickness $(\tau=$ $H_{R} / \lambda_{0}$ ) varies from 4 to 22 depending on loading and type of catalyst.

The LVRPA $/ I_{0}$ at irradiated surface of the reactor increases with catalyst concentration due to the amount of surface-exposed catalyst and back-scattering energy absorption from internal layer inside the reactor. These results agree with the literature [20]. In addition, it was found that the distribution of LVPRA is similar when the apparent optical thickness is used in annular and CPCs reactors [31].

The change of LVRPA $/ I_{0}$ with respect to $y$ near the irradiated surface is associated with extinction coefficients; the total energy available in the system is quickly extinguished by increases in catalyst concentration and high extinction coefficients $\beta$.

Finally, the distance from the surface $(y=0)$ where the radiant energy is absorbed (i.e., boundary layer thickness) depends on concentration and type of catalyst. For catalyst loading greater than $0.3 \mathrm{~g} / \mathrm{l}$, the LVRPA $/ I_{0}$ at the bottom of the reactor is negligible.

To validate the SFM in a flat plate reactor, the model was run against rigorous solution of RTE proposed by $[9,36]$. The reported reactor had $1.2 \mathrm{~cm}$ of thickness, UV lamps as radiation source, Aldrich and Degussa P-25 as photocatalysts. The SFM parameters were calculated to the experimental conditions reported $\left(\left\langle I_{0}\right\rangle \approx 1.81 \times 10^{-8}\right.$ Einstein $\mathrm{cm}^{-2} \mathrm{~s}^{-1}$, catalyst Aldrich, $\langle\sigma\rangle=3.60 \times 10^{4} \mathrm{~cm}^{2} \mathrm{~g}^{-1}$, and $\langle\kappa\rangle=3.28 \times$ $10^{3} \mathrm{~cm}^{2} \mathrm{~g}^{-1}$ ) with a local percent error of LVRPA lower than 12 , and 2.4 for VRPA.

3.3. Design of Reactors. Figure 3 shows the VRPA $/ I_{0}$ profiles (2) in solid lines as a function of catalyst loading inside a flat plate reactor, for six different commercial brands of $\mathrm{TiO}_{2}$ catalysts. The dashed lines represent the values of $\delta_{\mathrm{abs}}$ that satisfy (1).

For all catalysts, a catalyst loading less than $0.2 \mathrm{~g} / \mathrm{l}$ has low rate of photon absorption; from 0.2 to $0.4 \mathrm{~g} / 1$ there are high values of $\mathrm{VRPA} / I_{0}$ and thus the best operating conditions of the system are within this interval; loadings greater than $0.4 \mathrm{~g} / \mathrm{l}$ reach some form of saturation; therefore, there is no justification for extra consumption of catalyst.

From VRPA $/ I_{0}$ profile in Figure 3 and Table 2, it is established that the absorption of radiant energy is faster 


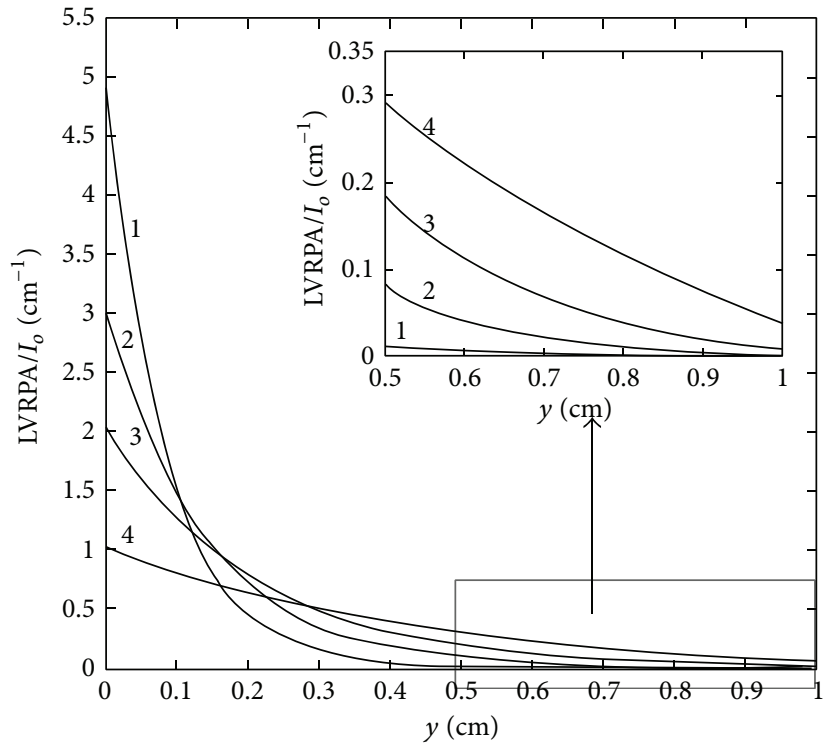

(a)

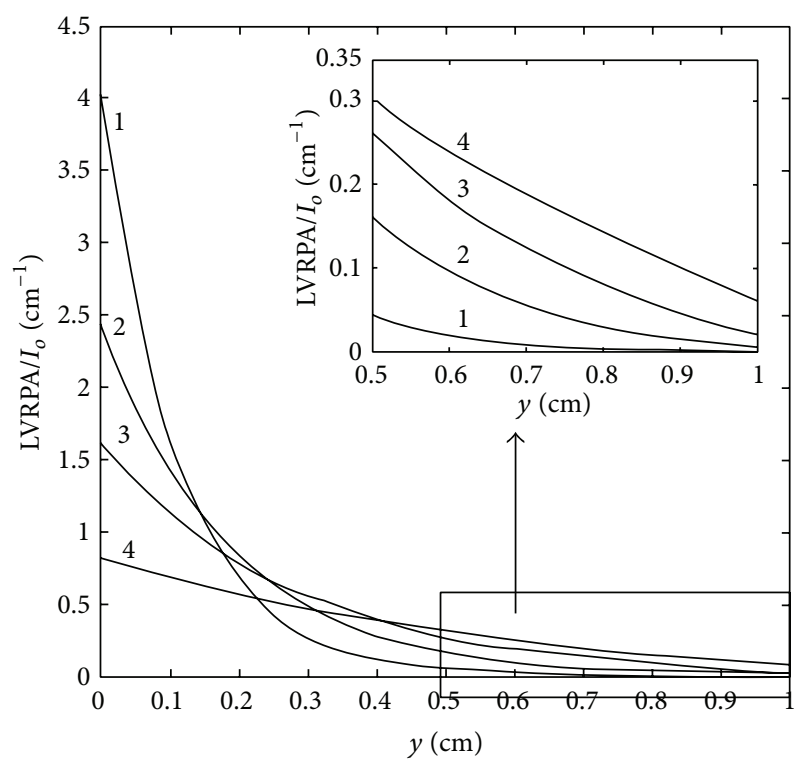

(b)

FIgURE 2: Profile of energy absorption rate (LVRPA/ $I_{0}$ ) through fluid ( $y$-coordinate) for Degussa P-25 (a) and Aldrich (b). Catalysts loading $\left(\mathrm{g} \cdot 1^{-1}\right)$ : line $1=0.5 ;$ line $2=0.3$; line $3=0.2 ;$ line $4=0.1$.

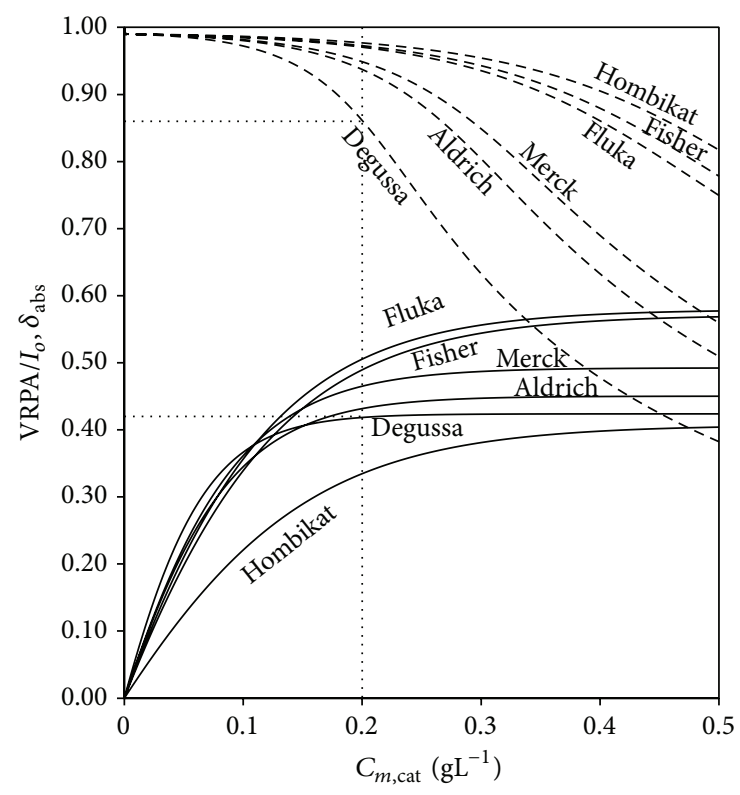

FIGURE 3: Design parameters of a flat plate solar photoreactor for different commercial brands of $\mathrm{TiO}_{2}$ as a function of its loading. VRPA $/ I_{0}\left(\mathrm{~cm}^{-1}\right)$ : $(-)$; boundary layer thickness of photon absorption $\delta_{\text {abs }}(\mathrm{cm}):(------)$.

for catalysts with a low coefficient of scattering albedo $\omega$. In other words, high absorption coefficients and low scattering coefficients have greater absorption of photons, increasing the mathematical relationship $1-\omega$. As a result, the absorption presents the following order: Fluka $>$ Fischer $>$ Merck $>$ Aldrich $>$ Degussa P-25 $>$ Hombikat.
The catalyst Aldrich has a maximum VRPA 7\% higher than the one presented by the catalyst Degussa. A similar trend was reported for polychromatic radiation using UV lamps, where the catalyst Aldrich is 19\% more efficient than Degussa P-25 [36].

For all catalysts and loadings lower than $0.1 \mathrm{~g} / \mathrm{l}$, the absorption of photons occurs in the entire thickness of the reactor $(1 \mathrm{~cm})$, but the VRPA has small values. Catalyst loadings between 0.1 and $0.2 \mathrm{~g} / \mathrm{l}$ employ the entire thickness of the reactor with approximately zero values of the LVRPA at the bottom of the reactor and begin to show a boundary layer of photon absorption thinner than $1 \mathrm{~cm}$, due to some form of saturation between photon transport and the catalyst amount to absorb them.

For catalyst loading higher than $0.2 \mathrm{~g} / \mathrm{l}$, different boundary layer thicknesses of absorption can be seen. Catalysts with higher coefficient of photon extinction have a thinner boundary layer because the energy is quickly extinguished as it travels through the fluid.

However, Hombikat catalyst has the largest boundary layer of photon absorption, despite having an intermediate value of extinction coefficient; this is due to its low absorption coefficient $\kappa$ and its high coefficient of scattering albedo $\omega$; most of the photons are dispersed in a large layer of fluid phase with a photon absorption rate slower than other catalysts.

Profile of boundary layer thickness of photon absorption represents the best conditions of design. A point above this curve presents a dark layer inside reactor, while a point below it presents VRPA less than the maximum possible.

3.4. Optimal Configuration of Reactors. Figure 3 provides useful information to define the design thickness of a flat 
plate reactor and type and loading of catalyst. For applications in very thin reactors (e.g., thin films of continuous fluid by sliding on an inclined flat plate), the catalyst with the best performance is Degussa P- 25 followed by Aldrich; the catalyst selection is based on reactor thickness. On the other hand, for applications in very thick reactors, the catalyst with the best performance is Fluka followed by Fischer; the catalyst selection is based on the greater amount of energy absorbed.

To design a photoreactor using a specific catalyst, for example, Degussa P-25 (point line), the VRPA $/ I_{0}$ profile in Figure 3 recommends $0.2 \mathrm{~g} / \mathrm{l}$ of catalyst to take the maximum energy absorbed with the minimum consumption of catalyst. The $\delta_{\text {abs }}$ profile in the same figure suggests a design thickness of reactor equal to or slightly higher than $0.86 \mathrm{~cm}$ and take advantage of the entire volume within the reactor for the photon absorption. Table 3 was reported using the procedure above.

The optimum catalyst loading was calculated for catalysts water system; this increases in systems where there is absorption of radiant energy by substrate. Other authors have reported optimum values of catalyst loading similar to those reported in this paper. Brandi et al. report a loading close to $0.3 \mathrm{~g} / \mathrm{l}$ based on the simulation of photon absorption for Aldrich and Degussa catalysts with radiation from UV lamps in a flat plate reactor $[20,36]$.

Experimental researches developed at the solar platform from Almeria obtained an optimal loading of Degussa P25 in a plate flat solar reactor equal to $0.2 \mathrm{~g} / 1$ [37-39]; this concentration is the same obtained by simulation in this work.

Different geometries are not comparable; however, the reported values of optimum catalyst loading have proved to be very similar in different reactors. An example of this result is the work made by Colina-Márquez and coworkers. They found optimum catalyst loadings from 0.17 to $0.4 \mathrm{~g} / \mathrm{l}$ for catalysts with scattering albedo between 0.75 and 0.95 in a CPC solar reactor and catalyst loadings between 0.2 and $0.6 \mathrm{~g} / \mathrm{l}$ for a tubular reactor [19]. Particularly, they obtained $0.21 \mathrm{~g} / \mathrm{l}$ as optimal loading for Degussa P-25.

For thicknesses not near $1 \mathrm{~cm}$, it is recommended to use the design parameter called apparent optical thickness $\tau_{\text {app }}=\tau a \sqrt{1-\omega_{\text {corr }}^{2}}$, where $\tau=H_{R} \beta C_{m \text {, cat }}$; the parameter was proposed by [19] and modified here for its application to flat plate reactor. At conditions reported in Table 2, the $\tau_{\text {app }}$ values obtained were 4.39, 4.08, 4.15, 3.77, 3.99, and 4.10 to Aldrich, Degussa, Merck, Hombikat, Fisher, and Fluka, respectively. The best design conditions for different catalyst loadings and reactor thicknesses are obtained by keeping $\tau_{\text {app }}$ constant.

Reactor design information presented in this paper is useful to determine the optimum catalyst loading, the optimal thickness of reactor, and the radiant energy absorbed. In addition, it eliminates the need of statistical analysis of experiment design which involves considerable consumption of time and resources [19]. New photocatalysts can be analyzed using the methodology presented here by varying absorption and scattering coefficients.
TABLE 3: Optimum catalyst loading, maximum energy absorbed, and design thickness of flat plate reactor under solar radiation.

\begin{tabular}{lccc}
\hline Catalyst & $\begin{array}{c}\text { Loading } \\
(\mathrm{g} / \mathrm{L})\end{array}$ & $\begin{array}{c}\mathrm{VRPA}_{\text {max }} / I_{0} \\
\left(\mathrm{~cm}^{-1}\right)\end{array}$ & $\begin{array}{c}\text { Suggested thickness } \\
\text { of the reactor }(\mathrm{cm})\end{array}$ \\
\hline Degussa P-25 & 0.2 & 0.42 & 0.86 \\
Aldrich & 0.3 & 0.45 & 0.80 \\
Merck & 0.3 & 0.49 & 0.85 \\
Hombikat & 0.4 & 0.40 & 0.90 \\
Fisher & 0.4 & 0.56 & 0.88 \\
Fluka & 0.4 & 0.57 & 0.86 \\
\hline
\end{tabular}

\section{Conclusions}

This study has presented a new parameter for selection of thickness of a flat plate reactor called boundary layer thickness of photon absorption $\delta_{\text {abs }}$, which represents an effective thickness of absorption. Its use allows the elimination of dark zones within the reactor and absorption of the largest amount of photons. Also, together with the VRPA, it provides sufficient criteria for sizing of reactor thickness, the choice of catalyst, and its loading. Its use is applicable to the scale-up of solar reactors.

The parameter was evaluated for $\mathrm{TiO}_{2}$ semiconductors Degussa P-25, Aldrich, Merck, Hombikat, Fluka, and Fisher, as a function of reactor thickness, catalyst loading, and the maximum amount of energy absorbed getting optimal operating conditions in the catalyst loading.

\section{Nomenclature}

$a: \quad$ SFM parameter, dimensionless

$b$ : $\quad$ SFM parameter, dimensionless

$C_{m, \text { cat }}: \quad$ Catalyst concentration, $\mathrm{gl}^{-1}$

$F_{\text {obj: }}$ : Objective function, $\mathrm{mol}^{2} \mathrm{~cm}^{-6}$

$H: \quad$ Thickness, $\mathrm{cm}$

I: $\quad$ Emission spectrum of radiation source, Einstein $\mathrm{cm}^{-2} \mathrm{~s}^{-1}$

$I_{0}: \quad$ Flux of radiation at surface, Einstein $\mathrm{cm}^{-2} \mathrm{~s}^{-1}$

LVRPA: Local volumetric rate of photon absorption, Einstein $\mathrm{cm}^{-3} \mathrm{~s}^{-1}$

$p_{b}$ : $\quad$ Probability of backward scattering, dimensionless

$p_{f}: \quad$ Probability of forward scattering, dimensionless

$p_{s}: \quad$ Probability of side scattering, dimensionless

$r_{p}: \quad$ Auxiliary coordinate in the photon flux

direction, $\mathrm{cm}$

$x: \quad$ Cartesian coordinate, $\mathrm{cm}$

$y: \quad$ Cartesian coordinate, $\mathrm{cm}$

$z: \quad$ Cartesian coordinate, $\mathrm{cm}$. 


\section{Greek Letters}

$\beta$ : $\quad$ Specific extinction coefficient, $\mathrm{cm}^{2} \mathrm{~g}^{-1}$

$\gamma: \quad$ SFM parameter, dimensionless

$\delta_{\text {abs }}$ : Boundary layer thickness of photon absorption, $\mathrm{cm}$

$\kappa: \quad$ Specific absorption coefficient, $\mathrm{cm}^{2} \mathrm{~g}^{-1}$

$\lambda$ : $\quad$ Radiation wavelength, $\mathrm{nm}$

$\lambda_{0}$ : $\quad$ Mean free path of photons, $\mathrm{cm}$

$\lambda_{\omega_{\text {corr }}}:$ Extinction length, $\mathrm{cm}$

$\sigma: \quad$ specific scattering coefficient, $\mathrm{cm}^{2} \mathrm{~g}^{-1}$

$\tau$ : Optical thickness, dimensionless

$\tau_{\text {app }}:$ Apparent optical thickness, dimensionless

$\omega: \quad$ Scattering albedo, dimensionless

$\omega_{\text {corr }}$ : Scattering albedo corrected, adimensional.

\section{Subscripts \\ corr: Corrected \\ max: Maximum \\ min: Minimum \\ $R: \quad$ Reactor \\ $s$ : Irradiated surface \\ $\infty$ : Bottom of reactor. \\ $\lambda: \quad$ Spectral.}

\section{Superscripts}

*: Specific.

Special Symbols

\langle\rangle : Average value.

\section{Conflict of Interests}

The authors declare that there is no conflict of interests regarding the publication of this paper.

\section{Acknowledgments}

The authors are grateful to Universidad del Valle for the financial support to produce this work and to Colciencias for the financial support during their Ph.D. studies. M. A. Mueses thanks Universidad de Cartagena for the financial support. Finally, the authors thank Fernando Otálvaro for the English revision.

\section{References}

[1] A. C. Affam and M. Chaudhuri, "Degradation of pesticides chlorpyrifos, cypermethrin and chlorothalonil in aqueous solution by $\mathrm{TiO}_{2}$ photocatalysis," Journal of Environmental Management, vol. 130, pp. 160-165, 2013.

[2] M. Tanveer and G. Tezcanli Guyer, "Solar assisted photo degradation of wastewater by compound parabolic collectors: review of design and operational parameters," Renewable and Sustainable Energy Reviews, vol. 24, pp. 534-543, 2013.
[3] J. Ângelo, L. Andrade, L. M. Madeira, and A. Mendes, "An overview of photocatalysis phenomena applied to $\mathrm{NO}_{x}$ abatement," Journal of Environmental Management, vol. 129, pp. 522539,2013

[4] K. Nakata and A. Fujishima, " $\mathrm{TiO}_{2}$ photocatalysis: design and applications," Journal of Photochemistry and Photobiology C: Photochemistry Reviews, vol. 13, no. 3, pp. 169-189, 2012.

[5] Z. Xing, X. Zong, J. Pan, and L. Wang, "On the engineering part of solar hydrogen production from water splitting: photoreactor design," Chemical Engineering Science, vol. 104, pp. 125-146, 2013.

[6] C. S. Turchi and D. F. Ollis, "Photocatalytic degradation of organic water contaminants: mechanisms involving hydroxyl radical attack," Journal of Catalysis, vol. 122, no. 1, pp. 178-192, 1990.

[7] D. I. Kondarides, V. M. Daskalaki, A. Patsoura, and X. E. Verykios, "Hydrogen production by photo-induced reforming of biomass components and derivatives at ambient conditions," Catalysis Letters, vol. 122, no. 1-2, pp. 26-32, 2008.

[8] J. Marugán, R. van Grieken, A. E. Cassano, and O. M. Alfano, "Intrinsic kinetic modeling with explicit radiation absorption effects of the photocatalytic oxidation of cyanide with $\mathrm{TiO}_{2}$ and silica-supported $\mathrm{TiO}_{2}$ suspensions," Applied Catalysis B: Environmental, vol. 85, no. 1-2, pp. 48-60, 2008.

[9] C. S. Zalazar, R. L. Romero, C. A. Martín, and A. E. Cassano, "Photocatalytic intrinsic reaction kinetics I: mineralization of dichloroacetic acid," Chemical Engineering Science, vol. 60, no. 19, pp. 5240-5254, 2005.

[10] J. Colina-Márquez, F. Machuca-Martínez, and G. Li Puma, "Photocatalytic mineralization of commercial herbicides in a pilot-scale solar CPC reactor: photoreactor modeling and reaction kinetics constants independent of radiation field," Environmental Science and Technology, vol. 43, no. 23, pp. 89538960, 2009.

[11] M. L. Satuf, R. J. Brandi, A. E. Cassano, and O. M. Alfano, "Photocatalytic degradation of 4-chlorophenol: a kinetic study," Applied Catalysis B: Environmental, vol. 82, no. 1-2, pp. 37-49, 2008.

[12] G. Li Puma, V. Puddu, H. K. Tsang, A. Gora, and B. Toepfer, "Photocatalytic oxidation of multicomponent mixtures of estrogens (estrone (E1), 17 $\beta$-estradiol (E2), 17 $\alpha$-ethynylestradiol (EE2) and estriol (E3)) under UVA and UVC radiation: photon absorption, quantum yields and rate constants independent of photon absorption," Applied Catalysis B: Environmental, vol. 99, no. 3-4, pp. 388-397, 2010.

[13] G. Li Puma, B. Toepfer, and A. Gora, "Photocatalytic oxidation of multicomponent systems of herbicides: scale-up of laboratory kinetics rate data to plant scale," Catalysis Today, vol. 124, no. 3-4, pp. 124-132, 2007.

[14] M. A. Mueses, F. Machuca-Martinez, and G. Li Puma, "Effective quantum yield and reaction rate model for evaluation of photocatalytic degradation of water contaminants in heterogeneous pilot-scale solar photoreactors," Chemical Engineering Journal, vol. 215-216, pp. 937-947, 2013.

[15] O. M. Alfano, M. I. Cabrera, and A. E. Cassano, "Photocatalytic reactions involving hydroxyl radical attack: I. Reaction kinetics formulation with explicit photon absorption effects," Journal of Catalysis, vol. 172, no. 2, pp. 370-379, 1997.

[16] M. Á. Mueses and F. Machuca-Martínez, "Mathematical model for non-intrinsic photonic yields in heterogeneous photocatalytic reactions," Información Tecnológica, vol. 23, no. 3, pp. 4350, 2012. 
[17] G. E. Imoberdorf, A. E. Cassano, H. A. Irazoqui, and O. M. Alfano, "Simulation of a multi-annular photocatalytic reactor for degradation of perchloroethylene in air: parametric analysis of radiative energy efficiencies," Chemical Engineering Science, vol. 62, no. 4, pp. 1138-1154, 2007.

[18] M. L. Satuf, R. J. Brandi, A. E. Cassano, and O. M. Alfano, "Scaling-up of slurry reactors for the photocatalytic degradation of 4-chlorophenol," Catalysis Today, vol. 129, no. 1-2, pp. 110-117, 2007.

[19] J. Colina-Márquez, F. MacHuca-Martínez, and G. L. Puma, "Radiation absorption and optimization of solar photocatalytic reactors for environmental applications," Environmental Science and Technology, vol. 44, no. 13, pp. 5112-5120, 2010.

[20] R. J. Brandi, O. M. Alfano, and A. E. Cassano, "Modeling of radiation absorption in a flat plate photocatalytic reactor," Chemical Engineering Science, vol. 51, no. 11, pp. 3169-3174, 1996.

[21] J. J. Duderstadt and E. R. Martín, Transport Theory, Wiley, New York, NY, USA, 1979.

[22] B. Toepfer, A. Gora, and G. Li Puma, "Photocatalytic oxidation of multicomponent solutions of herbicides: reaction kinetics analysis with explicit photon absorption effects," Applied Catalysis B: Environmental, vol. 68, no. 3-4, pp. 171-180, 2006.

[23] G. Li Puma, J. N. Khor, and A. Brucato, "Modeling of an annular photocatalytic reactor for water purification: oxidation of pesticides," Environmental Science and Technology, vol. 38, no. 13, pp. 3737-3745, 2004.

[24] G. Li Puma and A. Brucato, "Dimensionless analysis of slurry photocatalytic reactors using two-flux and six-flux radiation absorption-scattering models," Catalysis Today, vol. 122, no. 12, pp. 78-90, 2007.

[25] A. Brucato, A. E. Cassano, F. Grisafi, G. Montante, L. Rizzuti, and G. Vella, "Estimating radiant fields in flat heterogeneous photoreactors by the six-flux model," AIChE Journal, vol. 52, no. 11, pp. 3882-3890, 2006.

[26] G. Li Puma, "Dimensionless analysis of photocatalytic reactors using suspended solid photocatalysts," Chemical Engineering Research and Design, vol. 83, no. 7, pp. 820-826, 2005.

[27] A. E. Cassano, C. A. Martín, R. J. Brandi, and O. M. Alfano, "Photoreactor analysis and design: fundamentals and applications," Industrial and Engineering Chemistry Research, vol. 34, no. 7, pp. 2155-2201, 1995.

[28] J. Blanco Gálvez, S. Malato Rodríguez, J. Peral, B. Sánchez, and A. I. Cardona, "Diseño de reactores para fotocatálisis: evaluación comparativa de las distintas opciones," in Eliminación De Contaminantes Por Fotocatálisis Heterogénea, pp. 243-266, 2004.

[29] G. Li Puma and P. L. Yue, "Modelling and design of thin-film slurry photocatalytic reactors for water purification," Chemical Engineering Science, vol. 58, no. 11, pp. 2269-2281, 2003.

[30] F. P. Incropera and D. P. DeWitt, Fundamentals of Heat and Mass Transfer, John Wiley \& Sons, New York, NY, USA, 4th edition, 1996.

[31] J. Moreira, B. Serrano, A. Ortiz, and H. De Lasa, "Evaluation of photon absorption in an aqueous $\mathrm{TiO}_{2}$ slurry reactor using Monte Carlo simulations and macroscopic balance," Industrial and Engineering Chemistry Research, vol. 49, no. 21, pp. 1052410534, 2010.

[32] "Standard Tables for Reference Solar Spectral Irradiances: Direct Normal and Hemispherical on $37^{\circ}$ Tilted Surface. ASTM G173 03," ASTM International, 2012.
[33] M. I. Cabrera, O. M. Alfano, and A. E. Cassano, "Absorption and scattering coefficients of titanium dioxide participate suspensions in water," Journal of Physical Chemistry, vol. 100, no. 51, pp. 20043-20050, 1996.

[34] M. L. Satuf, R. J. Brandi, A. E. Cassano, and O. M. Alfano, "Experimental method to evaluate the optical properties of aqueous titanium dioxide suspensions," Industrial and Engineering Chemistry Research, vol. 44, no. 17, pp. 6643-6649, 2005.

[35] R. J. Brandi, G. Rintoul, O. M. Alfano, and A. E. Cassano, "Photocatalytic reactors-reaction kinetics in a flat plate solar simulator," Catalysis Today, vol. 76, no. 2-4, pp. 161-175, 2002.

[36] R. J. Brandi, O. M. Alfano, and A. E. Cassano, "Rigorous model and experimental verification of the radiation field in a flat-plate solar collector simulator employed for photocatalytic reactions," Chemical Engineering Science, vol. 54, no. 13-14, pp. 2817-2827, 1999.

[37] S. Malato Rodríguez, J. Blanco Gálvez, M. I. Maldonado Rubio et al., "Engineering of solar photocatalytic collectors," Solar Energy, vol. 77, no. 5, pp. 513-524, 2004.

[38] J. Giménez, D. Curcó, and M. A. Queral, "Photocatalytic treatment of phenol and 2,4-dichlorophenol in a solar plant in the way to scaling-up," Catalysis Today, vol. 54, no. 2-3, pp. 229243, 1999.

[39] S. Malato, J. Blanco, A. Vidal et al., "New large solar photocatalytic plant: set-up and preliminary results," Chemosphere, vol. 47, no. 3, pp. 235-240, 2002. 

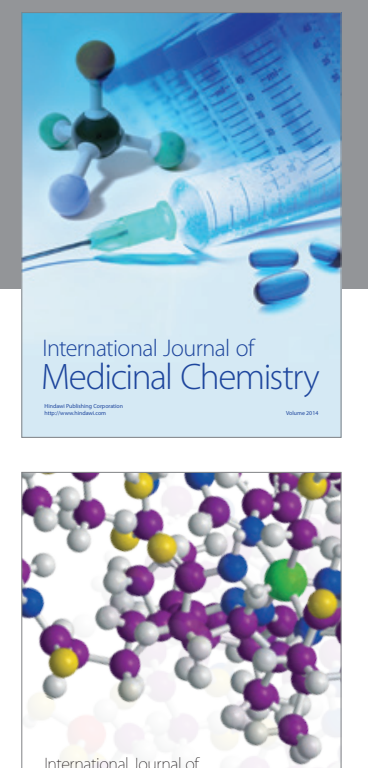

\section{Carbohydrate} Chemistry

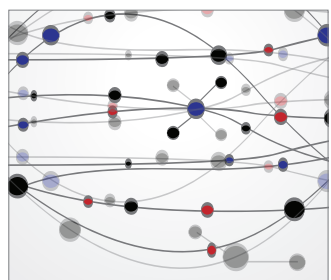

The Scientific World Journal
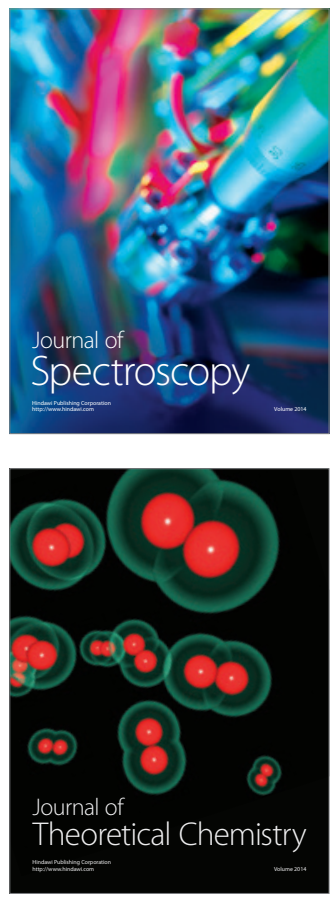
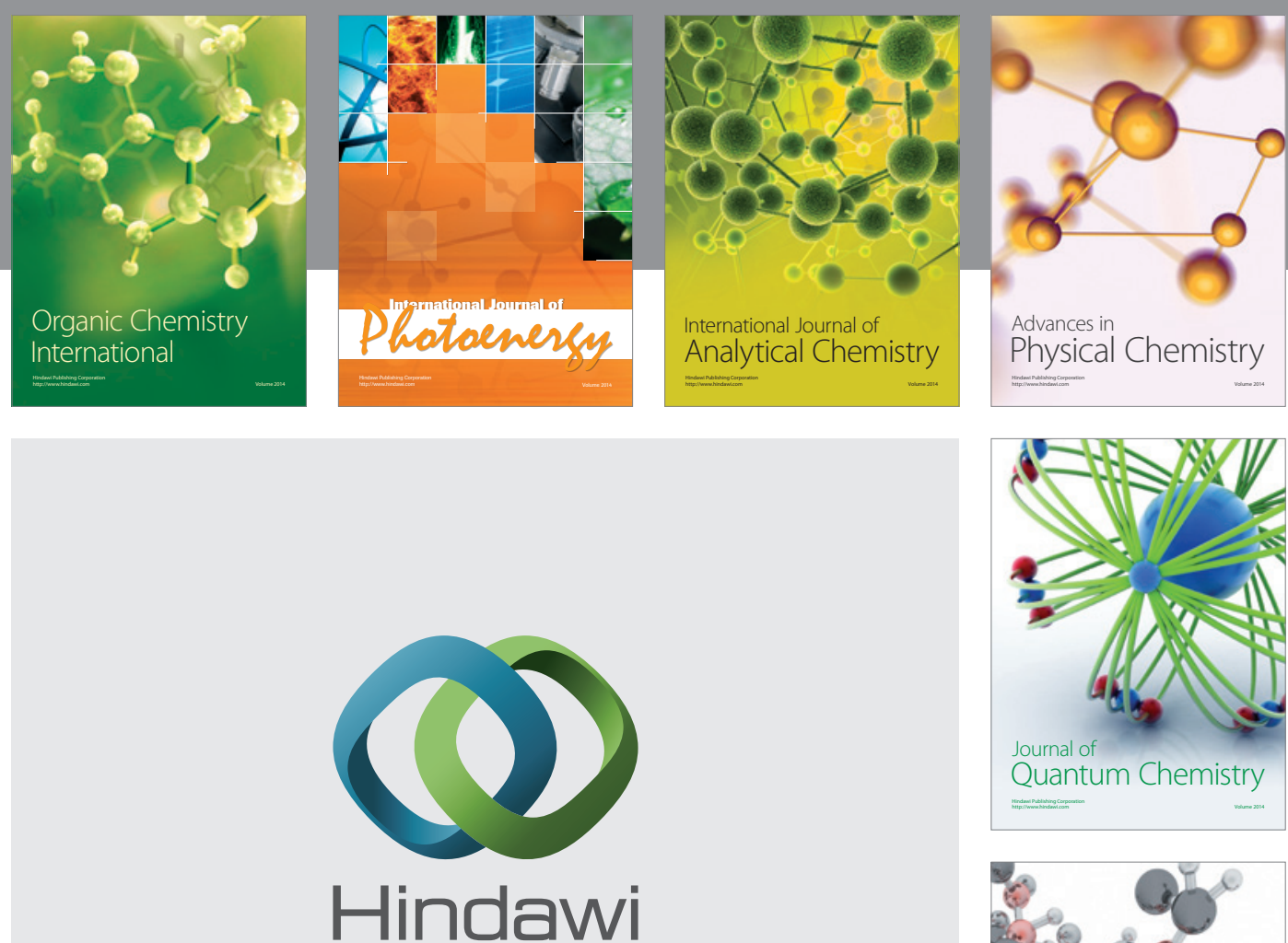

Submit your manuscripts at

http://www.hindawi.com

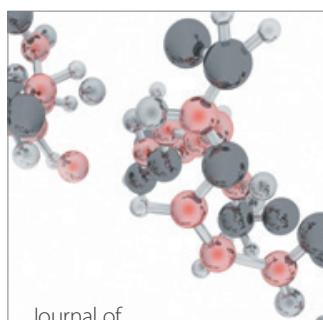

Analytical Methods

in Chemistry

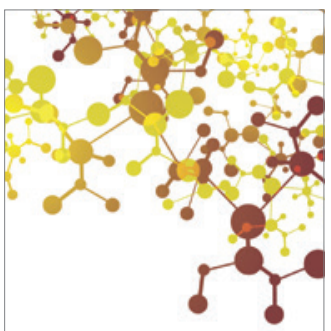

Journal of

Applied Chemistry

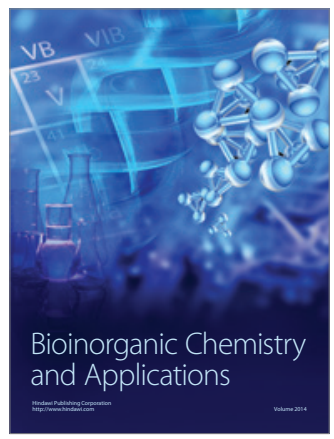

Inorganic Chemistry
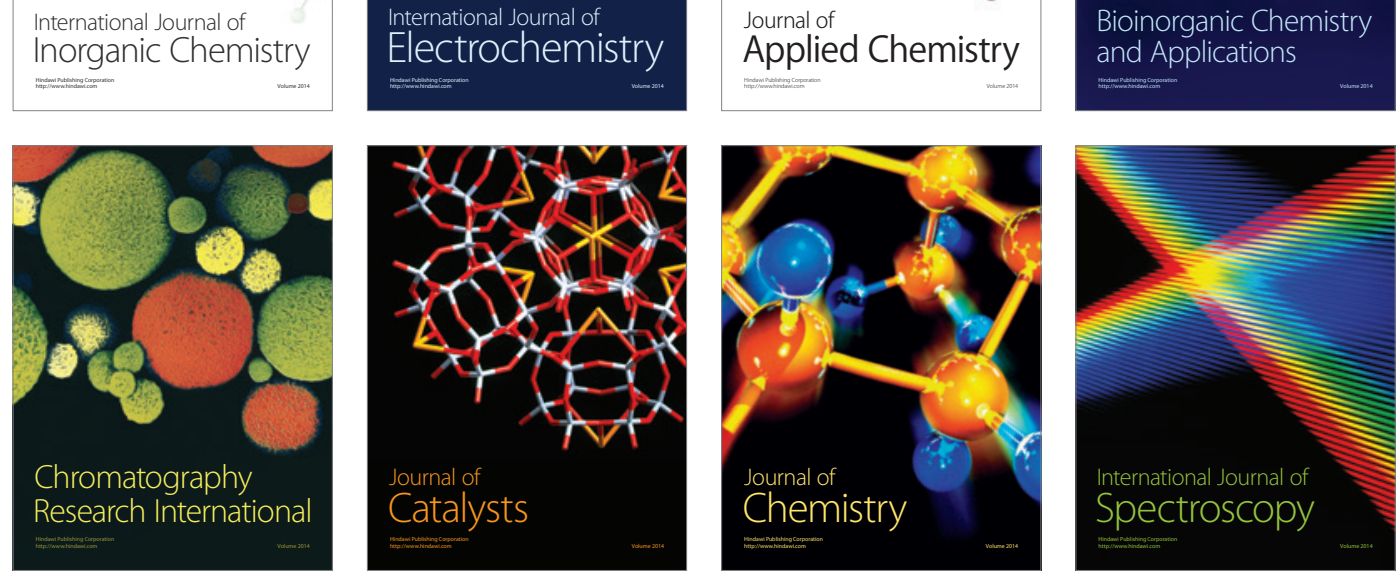